\title{
Interaction of arsenic species with tropical river aquatic humic substances enriched with aluminum and iron
}

\author{
Lilian Karla de Oliveira ${ }^{1,2}$ - Camila de Almeida Melo ${ }^{1,2}$ - Leonardo Fernandes Fraceto ${ }^{2}$. \\ Kurt Friese $^{3}$ - André Henrique Rosa ${ }^{2}$
}

Received: 10 April 2015 / Accepted: 16 November 2015 /Published online: 26 November 2015

(C) Springer-Verlag Berlin Heidelberg 2015

\begin{abstract}
The mobility and bioavailability of arsenic (As) are strongly controlled by adsorption/precipitation processes involving metal oxides. However, the organic matter present in the environment, in combination with these oxides, can also play an important role in the cycle of arsenic. This work concerns the interaction between As and two samples of aquatic humic substances (AHS) from tropical rivers. The AHS were extracted as proposed by IHSS, and were characterized by ${ }^{13} \mathrm{C}$ NMR. The experiments were conducted with the AHS in natura and enriched with metal cations, with different concentrations of As, and complexation capacity was evaluated at three different $\mathrm{pH}$ levels (5.0, 7.0, and 9.0). The AHS samples showed similar chemical compositions. The results suggested that there was no interaction between As(III) and AHS in natura or enriched with Al. Low concentrations of $\mathrm{As}(\mathrm{V})$ were bound to AHS in natura. For As(III), the complexation capacity of the AHS enriched with Fe was approximately $48 \mu \mathrm{mol}$ per $\mathrm{g}$ of $\mathrm{C}$, while the values for $\mathrm{As}(\mathrm{V})$ were in the range 69-80 $\mu \mathrm{mol}$ per grams of C. Fluorescence spectra showed that changes in Eh affected the complexation reactions of $\mathrm{As}(\mathrm{V})$ species with AHS.
\end{abstract}

Responsible editor: Philippe Garrigues

Lilian Karla de Oliveira

1.koliveira@yahoo.com.br

1 Department of Analytical Chemistry, Institute of Chemistry, UNESP, Rua Prof. Francisco Degni, 55, Araraquara 18087-180, São Paulo, Brazil

2 Department of Environmental Engineering, UNESP, Av. Três de Março, 511, Sorocaba 18087-180, São Paulo, Brazil

3 UFZ-Helmholtz Centre for Environmental Research, Bruckstrasse 3a, 39114 Magdeburg, Germany
Keywords Arsenic - Aquatic humic substances · Complexation · Aluminum · Iron

\section{Introduction}

Arsenic (As), a potentially toxic metalloid, has been found at high concentrations in groundwater in countries including Mexico, China, and Bangladesh, among others (Li et al. 2013; Sarkar et al. 2010; Song et al. 2006). In Brazil, the areas contaminated with As are mainly associated with gold or iron mining. In some contaminated locations, the As concentration can be greater than $2.9 \mathrm{mg} \mathrm{L}^{-1}$, exceeding the maximum As concentration in groundwater recommended by the World Health Organization (WHO), which is $10 \mu \mathrm{g} \mathrm{L}^{-1}$ (Borba et al. 2003; de Figueiredo et al. 2007; Pimentel et al. 2003).

In the environment, As can be present as organic or inorganic forms, with two main chemical species: As(III), found under reducing conditions, and $\mathrm{As}(\mathrm{V})$, found under oxidizing conditions (Sharma and Sohn 2009; Wang and Mulligan 2006). In neutral media, the As(III) species is more toxic and mobile than $\mathrm{As}(\mathrm{V})$, but both species coexist in solution, and the speciation depends on redox conditions as well as factors such as the presence of microbes, reactive minerals, and organic matter (OM) (Sharma and Kappler 2011). Several studies have reported the interaction of As with clay, Fe oxides/hydroxides, soils, and sediments (Girouard and Zagury 2009; Grafe et al. 2001; Sharma and Kappler 2011). However, complexation with OM can also play an important role in the transport, transformation, and bioavailability of As but has received little research attention.

$\mathrm{OM}$, which is ubiquitous in the environment, is formed by the chemical and biological degradation of plant and animal residues. Humic substances (HS) are one of the main classes of $\mathrm{OM}$ and contain carboxylic, phenolic, and hydroxyl groups. 
The presence of these groups makes HS attractive for environmental remediation, because it is by means of these groups that the HS can bind to organic and inorganic pollutants, decreasing the toxicity and availability of these substances in the environment (Batista et al. 2009; Botero et al. 2011; Gungor and Bekbolet 2010; Ruiz et al. 2013; Zhou et al. 2005).

The formation of As-OM complexes has recently been reported. Some studies have suggested the formation of binary complexes by direct binding of As with OM (Buschmann et al. 2006; Liu and Cai 2010; Mandal et al. 2013; Warwick et al. 2005). Other work has shown the complexation of As with $\mathrm{OM}$ in the presence of iron. This cation acts as a bridge in formation of a ternary As-Fe-OM complex (Liu et al. 2011; Mikutta and Kretzschmar 2011; Sharma et al. 2010). Such studies enable a better understanding of the processes affecting the availability of As in the environment and can assist in the remediation of contaminated areas (which can proceed under natural conditions in water bodies). The aim of this work was to obtain information on the complexation of As in tropical rivers, where there can be high concentrations of cations, notably aluminum ( $\mathrm{Al})$ and iron $(\mathrm{Fe})$, as well as the ubiquitous presence of $\mathrm{OM}$. There have been few reports in the literature concerning the interactions of As, $\mathrm{OM}, \mathrm{Al}$, and $\mathrm{Fe}$. Here, the complexation of As (considering As(III) and $\mathrm{As}(\mathrm{V})$ ) by aquatic humic substances (AHSs) from tropical rivers was evaluated by simulating the conditions of rivers rich in $\mathrm{Al}, \mathrm{Fe}$, and $\mathrm{OM}$.

\section{Materials and methods}

\section{Sampling and characterization of water samples}

The water samples were collected from the rivers Sorocabinha and Itapanhaú (denoted SR and IR, respectively). The
Itapanhaú River is located in the Serra do Mar State Park, in Bertioga, São Paulo State, Brazil (2350’23”S; 4608’21”W). The Sorocabinha River is situated next to the Juréia Ecological Station, in Iguape, São Paulo State, Brazil $\left(24^{\circ}\right.$ $\left.41^{\prime} 59^{\prime \prime} \mathrm{S} ; 47^{\circ} 33^{\prime} 05^{\prime \prime} \mathrm{W}\right)$. Water samples (100 L) were collected from the rivers in polyethylene bottles. The physical-chemical parameters $\mathrm{pH}$, temperature, electrical conductivity, and dissolved oxygen content were monitored in situ using calibrated portable meters: WTW $315 \mathrm{i} \mathrm{pH}$ meter, WTW LF 330 conductivity meter with TetraCon 325 cell, and WTW Oxi 315i oxygen meter with CellOx 325 sensor. The concentrations of elements ( $\mathrm{Al}, \mathrm{Cr}, \mathrm{Fe}$, and $\mathrm{Zn})$ were determined using an Agilent 700 ICP-OES system.

\section{Extraction, characterization, and metal enrichment of the AHS}

The extraction employed XAD-7 resin that had been pretreated with $\mathrm{NaOH}, \mathrm{HCl}$, and methanol solutions to remove any impurities. The AHSs were extracted from water of the SR (AHS-S) and IR (AHS-I) rivers by adsorption on chromatography columns, as described by Thurman and Malcolm (1981) and the International Humic Substances Society (IHSS) (Sargentini et al. 2001).

The AHSs were characterized by ${ }^{13} \mathrm{C}$ NMR with cross polarization (CP) and magic-angle spinning (MAS), using a Bruker Avance III spectrometer operated at $400 \mathrm{MHz}$, with $5 \mathrm{kHz}$ rotation, $2 \mathrm{~ms}$ contact time, $5 \mathrm{~s}$ relaxation time, and 11,000 accumulated scans. Specific areas of the spectra obtained were integrated, and the data were used to calculate the aromaticity degree (AD) of the AHS according to Eq. 1.

$$
A D(\%)=\frac{(\text { aromatic } C+\text { aromatic } O)}{(\text { alkyl } C+N \text { alkyl } C+O \text { alkyl } C+\text { aromatic } C+\text { aromatic } O+\text { carboxyl }+ \text { carbonyl })} \times 100
$$

The concentrations of total organic carbon (TOC) in the water samples, AHS-S and AHS-I solutions were determined by catalytic combustion in a flow of oxygen, with subsequent detection using a Shimadzu TOC-500 analyzer.

Excitation-emission matrices were obtained using a Skalar (The Netherlands) Fluo-Imager M53 spectrofluorometer equipped with a xenon lamp and a photomultiplier. The AHS solutions were scanned over an excitation range of 240 to $500 \mathrm{~nm}$ in increments of $3 \mathrm{~nm}$ and in an emission wavelength in the range of $260-600 \mathrm{~nm}$ in increments of $3 \mathrm{~nm}$.

Enrichment of the AHS with metals ( $\mathrm{Al}$ or $\mathrm{Fe}$ ) was performed using AHS solutions $\left(50 \mathrm{mg} \mathrm{L}^{-1}\right.$ ), which were added to beakers containing solutions with metal cations $\left(\mathrm{FeCl}_{3}\right.$ or $\mathrm{AlCl}_{3}$ ), in a proportion of $100 \mathrm{mg}$ of metal per gram of AHS. The beakers were then maintained under constant agitation for $24 \mathrm{~h}$. The amount of metals complexed by AHS (Fe or Al) was determined as the difference between the amounts of added and free metals after reaction time using the tangential flow ultrafiltration method (Burba et al. 2001). The metal concentrations were determined by atomic emission spectroscopy using an Agilent 700 ICP-OES system. The final enriched solutions contained 6.5 and $9.6 \%$ of $\mathrm{Fe}$ and $\mathrm{Al}$, respectively. The enriched solutions were used to evaluate the complexation of As species by AHS metals. 


\section{Interactions between AHS and As species}

In order to evaluate the interaction between AHS and As species, complexation experiments were conducted using AHS in natura or AHS enriched with Al(III) or Fe(III). Firstly, complexation experiments were made with AHS in natura, and after the data analysis, experiments were conducted with AHS enriched. Based on the TOC concentrations of both rivers, the experiments were performed using AHS solutions at concentrations of $50 \mathrm{mg} \mathrm{L}^{-1}$ (Table 1).

The complexation experiments employed $100 \mathrm{~mL}$ of AHS, in natura or enriched with metal (Al(III) or Fe (III)) and As species (As(III) or As(V)) at concentrations of $1.4 \mu \mathrm{mol} \mathrm{L}^{-1}$. The $\mathrm{pH}$ was adjusted to 7.0 using dilute solutions of $\mathrm{HCl}$ and/or $\mathrm{NaOH}$. The mixtures were kept under constant agitation. Arsenic complexation was determined as the difference between the amounts of added and free arsenic of the reaction time. The tangential flow ultrafiltration method was used to separate the free arsenic species from the arsenic complexed by the AHS, with aliquots $(2.0 \mathrm{~mL})$ being ultrafiltered (using ultracel regenerated cellulose membranes, $1 \mathrm{kDa}$ and $76 \mathrm{~mm}$; flow: $2 \mathrm{~mL} \mathrm{~min}^{-1}$ ) after predetermined time intervals (Burba et al. 2001). The experiments to evaluate the complexation capacity were performed using successive titrations of different concentrations of arsenic species (0.3$10.7 \mu \mathrm{mol} \mathrm{L}{ }^{-1}$ ) with aquatic humic substances enriched with metals (AHS-M) solution $\left(50.0 \mathrm{mg} \mathrm{L}^{-1}\right)$, each for a period of $60 \mathrm{~min}$, at three different $\mathrm{pH}$ values: 5.0, 7.0, and 9.0. Aliquots $(2.0 \mathrm{~mL})$ of the samples were then ultrafiltered, and the concentrations of free arsenic were determined by graphite furnace atomic absorption spectroscopy (Varian AA240), using the conditions recommended by the manufacturer. The detection limit (LOD) was $0.32 \mu \mathrm{g} \mathrm{L}^{-1}$. Fluorescence spectroscopy was used to evaluate the As-AHS complexes formed. All experiments were performed in triplicate.

Table 1 Physical-chemical parameters of water samples collected from the rivers Sorocabinha and Itapanhaú

\begin{tabular}{lll}
\hline Parameters & Sorocabinha & Itapanhaú \\
\hline $\mathrm{pH}$ & 5.00 & 4.50 \\
Temperature $\left({ }^{\circ} \mathrm{C}\right)$ & 23.0 & 21.0 \\
Conductivity $\left(\mu \mathrm{S} \mathrm{cm}{ }^{-1}\right)$ & 135 & 46.0 \\
Dissolved oxygen $\left(\mathrm{mg} \mathrm{L}^{-1}\right)$ & 4.10 & 4.20 \\
$\mathrm{Al}\left(\mu \mathrm{g} \mathrm{L}^{-1}\right)$ & 16.4 & 143 \\
$\mathrm{Cr}\left(\mu \mathrm{g} \mathrm{L}^{-1}\right)$ & 3.44 & 3.10 \\
$\mathrm{Fe}\left(\mu \mathrm{g} \mathrm{L}^{-1}\right)$ & 18.2 & 229 \\
$\mathrm{Zn}\left(\mu \mathrm{g} \mathrm{L}^{-1}\right)$ & $<\mathrm{LOD}$ & 71.8 \\
$\mathrm{TOC}\left(\mathrm{mg} \mathrm{L}^{-1}\right)$ & 18.9 & 15.9 \\
\hline
\end{tabular}

\section{Influence of redox potential (Eh)}

Samples of AHS-S, in natura or enriched with metals, were incubated in microcosms, with continuous control of $\mathrm{Eh}, \mathrm{pH}$, and temperature. Eight microcosms were set up, each consisting of a 2-L reactor, three electrodes to monitor Eh, $\mathrm{pH}$, and temperature, and a data acquisition system as described in $\mathrm{Yu}$ et al. (2007) and Frohne et al. (2011). Solutions of AHS-S $\left(50 \mathrm{mg} \mathrm{L}^{-1}\right)$ were added to the reactors, together with the metal ions, using $100 \mathrm{mg}$ of metal per gram of AHS. Solutions containing $1000 \mu \mathrm{g} \mathrm{L}^{-1}$ of As(V) were then added to the reactors, and the final volumes were adjusted to $2000 \mathrm{~mL}$. The experiments were conducted in two stages, each with duration of $8 \mathrm{~h}$. The first stage was under $\mathrm{N}_{2}$ flow $\left(30 \mathrm{~mL} \min ^{-1}\right.$ ), while the second stage was under $\mathrm{O}_{2}$ flow $\left(30 \mathrm{~mL} \mathrm{~min}^{-1}\right)$. Throughout the experiment, the temperature of the microcosms was maintained at $25^{\circ} \mathrm{C}$, and the $\mathrm{pH}$ was free (there was no $\mathrm{pH}$ adjustment in the experiments). The Eh, $\mathrm{pH}$, and temperature data for each microcosm were measured automatically every $10 \mathrm{~min}$. The microcosms were kept under constant agitation. Aliquots of $10 \mathrm{~mL}$ were removed with a syringe at predetermined time intervals $(0,1,2,4,6$, and $8 \mathrm{~h})$, filtered using a $0.45-\mu \mathrm{m}$ membrane (Millipore), and stored for subsequent analysis by fluorescence. The experiments were performed in triplicate.

\section{Results and discussion}

\section{AHS characterization}

Low $\mathrm{pH}$ and dissolved oxygen values were observed for both rivers, resulting from the high concentrations of OM. The Sorocabinha River showed higher electrical conductivity compared to the Itapanhaú River, which could be explained by marine salinity in this area (Table 1). The concentrations of the metals $\mathrm{Al}, \mathrm{Cr}, \mathrm{Fe}$, and $\mathrm{Zn}$ were within the ranges observed for other rivers rich in organic matter (Mora et al. 2009; Pokrovsky and Schott 2002). Among the metals studied, Al and $\mathrm{Fe}$ (Sorocabinha River) and $\mathrm{Al}, \mathrm{Fe}$, and $\mathrm{Zn}$ (Itapanhaú River) showed the highest concentrations, but these results are associated to geological weathering process considering that the rivers are located in Juréia Ecological Station and Serra do Mar State Park, respectively, both in an Environmental Protection Area of Sao Paulo State, Brazil.

The AHS samples extracted from the SR (AHS-S) and IR (AHS-I) rivers were characterized by ${ }^{13} \mathrm{C}$ NMR. This technique provides information about the different organic groups present in the molecules, helping in characterization of the AHS. From integration of the ${ }^{13} \mathrm{C}$ NMR spectra in different regions, it is possible to estimate the percentages and types of carbons present. The ${ }^{13} \mathrm{C}$ NMR spectra were divided into seven chemical shift regions (Table 2), with shifts in the 0 
$45 \mathrm{ppm}$ region attributed to alkyl carbons, shifts in the 45$60 \mathrm{ppm}$ region to $\mathrm{N}$-alkyl groups, and shifts in the 60 $110 \mathrm{ppm}$ region to O-alkyl groups. Shifts of aromatics and O-aromatics were identified in the 110-140 and 140160 ppm regions, respectively. The regions between 160 185 and 185-245 ppm were associated with the shifts of carboxylic carbon and carbonyls, respectively.

The AHS samples showed only small differences in organic composition (Table 2), with the largest groups in both cases being carbons bonded to ethers and hydroxyl groups, aromatic carbons, and carboxyl groups. Among the main characteristics of AHS are their complexity and stability, which are directly related to the chemical and microbial decomposition processes. Knowing that the rate of decomposition follows the descending order: phenols $>$ lipids $>$ lignin $>$ sugars, AHS with high levels of aromatic, carboxylic, and phenolic carbons have undergone greater humification (Rosa et al. 2000). High aromaticity degree (AD) values (36.5 and $35.2 \%$ for AHS-S and AHS-I, respectively) were obtained for both AHS samples, which were higher than reported in by Santin et al. (2008) (AD values between 23.8-31.6\%). The total organic carbon contents of the AHS solutions (Table 2) also showed similarity, with a slightly higher value for AHS-S. The results obtained in this work were similar to those reported previously for rivers rich in humic materials (Botero et al. 2011).

Fluorescence spectroscopy is a simple method that can be used to study the properties of HS (Mak and Lo 2011; Plaza et al. 2005). The utility of this technique is based on the presence of functional groups present in the HS, such as aromatic, phenolic, carboxylic, and quinone moieties, which have a high degree of condensation and can emit fluorescence. In addition, the redox properties give rise to unique fluorescence spectra. Figure 1 shows the excitation-emission matrices (EEM) for AHS-S and AHS-I, with the spectra divided into five regions. According to Chen et al. (2003), regions I, II, and IV are associated with the presence of aromatic proteins, while regions III and V are associated with fulvic and humic acids, respectively. Signals in region I could not be seen in the spectra, while low intensity signals in regions II and IV were indicative of low protein contents of these AHS samples. Higher intensities were observed in region III, for both AHS samples, characteristics of fulvic acids that are of lower molecular weight and possess more carboxylic groups and a greater number of complexation sites, compared to humic acids (Mak and Lo 2011; Melo et al. 2012; Winter et al. 2007). Higher intensities in region III were shown by AHS-I rather than by AHS-S.

\section{Complexation reaction between AHS and As}

\section{Interactions between AHS and As}

Figure 2 shows the interaction between the As species and the AHS samples in natura or enriched with Fe or Al. It can be seen that there were no observable interactions between As(III) and the AHS samples in natura (AHS-S and AHS-I) or enriched with $\mathrm{Al}$ (AHS-S-Al and AHS-I-Al). However, when AHS enriched with $\mathrm{Fe}$ was used, the initial As(III) concentrations decreased by approximately 63 and $51 \%$ for complexation with AHS-S-Fe and AHS-I-Fe, respectively. In the case of the As(V) species, there were small interactions with the AHS in natura: $0.1 \mu \mathrm{mol} \mathrm{L}{ }^{-1}(7 \%)$ and $0.13 \mu \mathrm{mol} \mathrm{L}{ }^{-1}(9 \%)$ for AHS-I and AHS-S, respectively. When enriched AHS was used, there were increases in the amounts of As complexed of 59 and $65 \%$ using the AHS-I-Al and AHS-S-Al, respectively, and 80 and $74 \%$ using the AHS-I-Fe and AHS-S-Fe, respectively.

It is known that at $\mathrm{pH} 7.0, \mathrm{As}(\mathrm{III})$ is found in neutral form $\left(\mathrm{H}_{3} \mathrm{AsO}_{3}\right)$ in the environment and that $\mathrm{As}(\mathrm{V})$ is negatively charged: $\mathrm{H}_{2} \mathrm{AsO}_{4}{ }^{-}(\mathrm{pKa}=2.3)$ and $\mathrm{HAsO}_{4}{ }^{2-}(\mathrm{pKa}=6.8)$. Since most of the active sites of AHS are ionized at $\mathrm{pH} 7.0$, charge repulsion is expected between $\mathrm{As}(\mathrm{V})$ species and active sites of the AHS, as well as interaction between arsenite and the carboxylic and phenolic groups of the AHS. However, this study showed that $\mathrm{As}(\mathrm{V})$ can bind directly to AHS by means of functional groups such as hydroxyl, phenolic, and carboxylic groups. Buschmann et al. (2006) suggested that this complexation is possible due to the high formal charge of $\mathrm{As}(\mathrm{V})$, additional to the effects of chelation and stabilization. Recent studies have shown that formation of As-DOM (arsenic and dissolved organic matter) complexes can result from the association of As with DOM, but it is necessary that the DOM should possess functional groups such as amines and sulfhydryl (Liu et al. 2011; Sharma et al. 2010). In addition, strong interactions have been observed between metal

Table 2 Relative percentages of different carbon groups present in the AHS samples, aromaticity degree and levels of total organic carbon

\begin{tabular}{|c|c|c|c|c|c|c|c|c|c|}
\hline & \multicolumn{7}{|c|}{ Chemical shift (ppm)/ Attributions (\%) } & \multirow[t]{2}{*}{$\mathrm{AD}(\%)$} & \multirow[t]{2}{*}{$\mathrm{TOC}\left(\mathrm{mg} \mathrm{L}^{-1}\right)$} \\
\hline & $\begin{array}{l}0-45 \\
\text { alkyl }\end{array}$ & $\begin{array}{l}45-60 \\
\text { N-alkyl }\end{array}$ & $\begin{array}{l}60-110 \\
\text { O-alkyl }\end{array}$ & $\begin{array}{l}110-140 \\
\text { aromatic }\end{array}$ & $\begin{array}{l}140-160 \\
\text { O-aromatic }\end{array}$ & $\begin{array}{l}160-185 \\
\text { carboxyl }\end{array}$ & $\begin{array}{l}185-245 \\
\text { carbonyl }\end{array}$ & & \\
\hline AHS-S & 9.0 & 6.0 & 30.0 & 24.0 & 14.0 & 21.0 & - & 36.5 & 19.7 \\
\hline AHS-I & 8.0 & 7.0 & 28.0 & 23.0 & 14.0 & 22.0 & 3.0 & 35.2 & 18.7 \\
\hline
\end{tabular}

$A D$ Aromaticity degree, TOC total organic carbon 


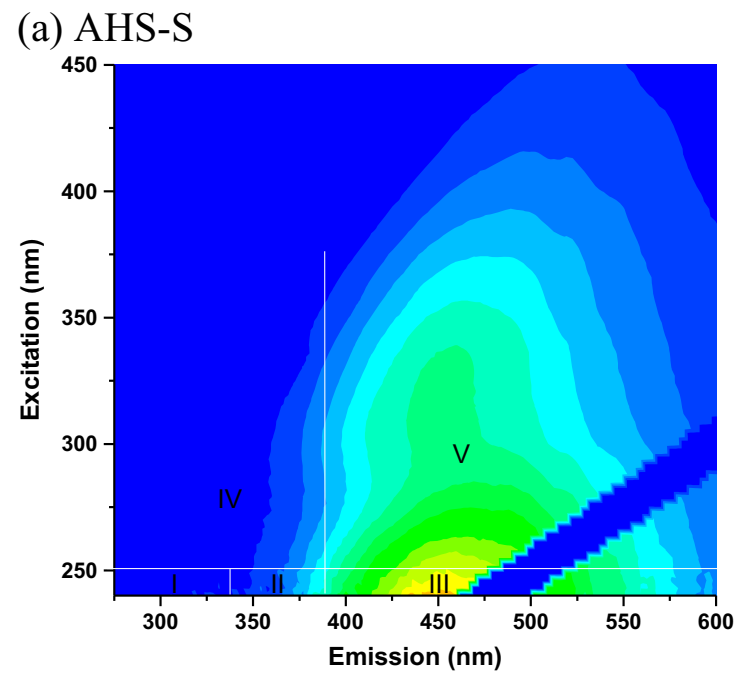

(b) AHS-I

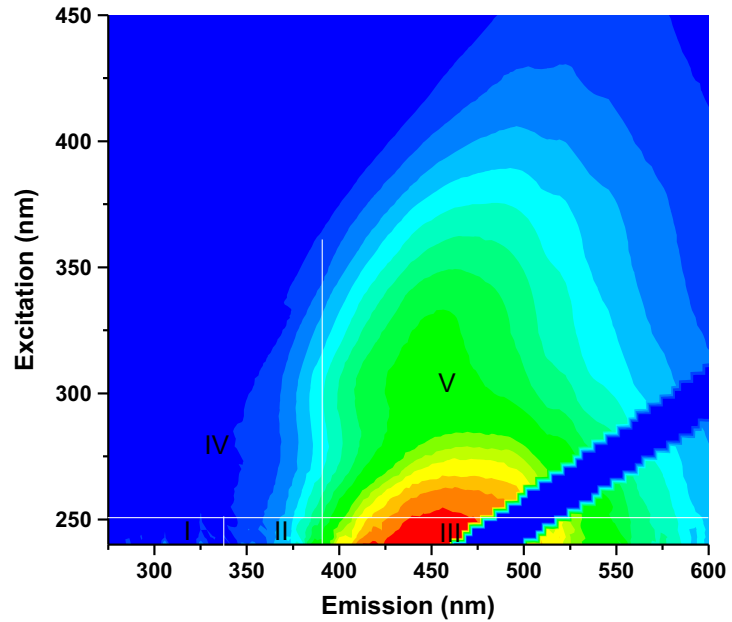

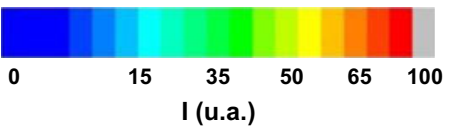

Fig. 1 Excitation-emission matrices (EEM) for the solutions of a AHS-S and $\mathbf{b}$ AHS-I

cations (Fe, $\mathrm{Zr}$, Ti, Mn, and $\mathrm{Al}$ ) and arsenic ions (Liu and Cai 2010; Mikutta and Kretzschmar 2011; Ritter et al. 2006). Higher values of $\mathrm{As}(\mathrm{V})$ complexed to AHS enriched with metals can be explained by electrostatic interactions between the positive charges of the AHS, which were "homogenized" with $\mathrm{Al} / \mathrm{Fe}$ ions and the negative charges of $\mathrm{As}(\mathrm{V})$ at $\mathrm{pH}$ 7.0.

\section{Influence of $p H$ and complexation capacity values}

It is known that the mechanisms of complexation of different metal ions by AHS are highly dependent on $\mathrm{pH}$, because at low $\mathrm{pH}$, the $\mathrm{H}^{+}$and metal cations tend to compete for the negatively charged active sites of the AHS (Limousin et al. 2007; Zhou et al. 2005). At high pH, greater amounts of metal

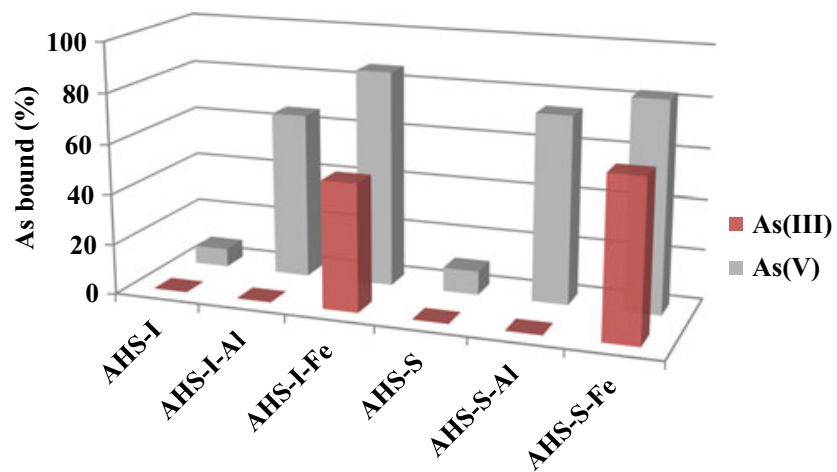

Fig. 2 Percentages of As(III) and As(V) species complexed by aquatic humic substances in natura (AHS-S and AHS-I) and enriched with $\mathrm{Al}$ or Fe ions (AHS-S-Al, AHS-I-Al, AHS-S-Fe, and AHS-I-Fe). Conditions: $\mathrm{pH} 7.0 ; 25^{\circ} \mathrm{C} ; 50 \mathrm{mg} \mathrm{L}^{-1}$ of AHS cations are bound by AHS. $\mathrm{As}(\mathrm{V})$ is present in the environment in anionic forms $\left(\mathrm{H}_{2} \mathrm{AsO}_{4}{ }^{-}\right.$and $\left.\mathrm{HAsO}_{4}{ }^{2-}\right)$, which could result in strong repulsion forces between $\mathrm{As}(\mathrm{V})$ species and AHS. It is expected that the addition of $\mathrm{Al} / \mathrm{Fe}$ ions to AHS should assist these reactions by decreasing the repulsion forces. Figure 3 shows the behaviors of $\mathrm{As}(\mathrm{III})$ and $\mathrm{As}(\mathrm{V})$ in the complexation capacity (CC) experiments, using the two AHS samples enriched with metals ( $\mathrm{Fe}$ and $\mathrm{Al})$ at different $\mathrm{pH}$ values. The $\mathrm{x}$-axes ([As]) of the graphs correspond to the concentrations of the free As species (As(III) or As(V)), while the y-axes ([As]b) correspond to the concentrations of As species bound by the complexation agents. From the slopes of the curves, it was possible to estimate the best $\mathrm{pH}$ for formation of the As-AHS complexes, with a steeper slope reflecting a greater amount of As species bound by the AHS.

Comparing the slopes of the curves for As(III), it can be seen that the concentrations bound by samples AHS-S-Fe and AHS-I-Fe increased with increasing $\mathrm{pH}$ and were highest for the basic medium ( $\mathrm{pH} 9.0$ ). At $\mathrm{pH}<9.0$, As(III) is present as a neutral species, suggesting that the mechanisms of formation of the complexes were similar up to this $\mathrm{pH}$ value. Greater complexation is expected at around $\mathrm{pH} 7.0$, because the active sites of the AHS are deprotonated and are more available. At $\mathrm{pH}$ higher than 9.0, As(III) can be present in the environment as anionic and neutral species so that more than one mechanism can be involved in formation of the As(III)-AHS complexes. In this case, in addition to the different As(III) species present, the mechanisms also involved the active sites of the AHS (phenolic, carboxylic, and hydroxyl groups) and the metal that was added to enrich the AHS. The As bound by AHS can result from association between the metal ion (for example, $\mathrm{Fe}$ ) and the AHS, forming AHS-M-As complexes. 

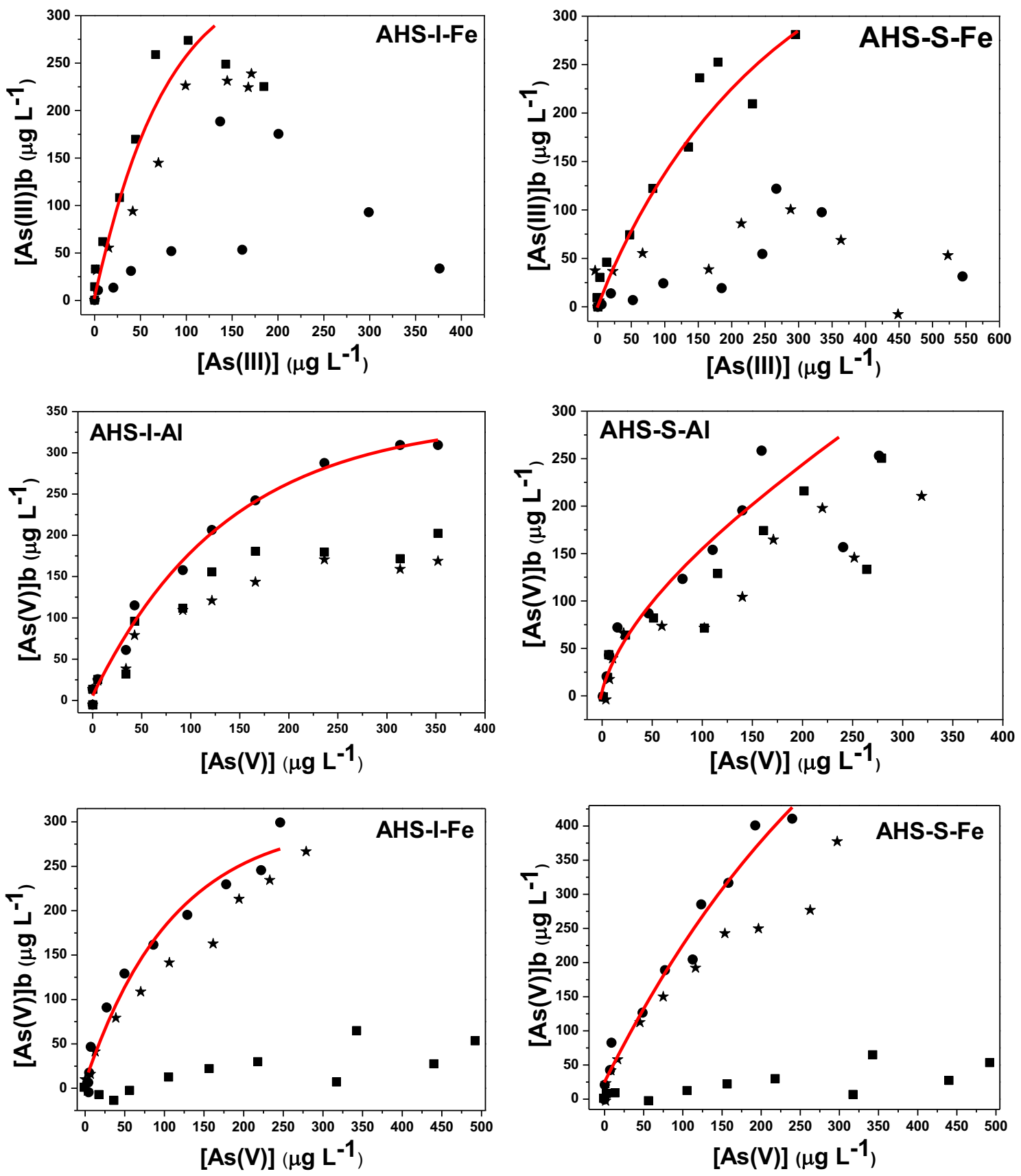

Fig. 3 Complexation capacity for arsenic species (As(III) and As(V)) determined for AHS enriched with $\mathrm{Fe}$ or Al, at $25^{\circ} \mathrm{C}$ and different $\mathrm{pH}$ values: 5.0 (circles), 7.0 (stars), and 9.0 (squares)

Therefore, at $\mathrm{pH}$ values higher than or equal to $\mathrm{pH} 9.0$, it is expected that greater amounts of As(III) are attracted to the AHS-Fe, because at this $\mathrm{pH}$, these species become negatively charged. At $\mathrm{pH}$ values higher than 5.0, the precipitation of ferric iron is also expected. However, due to the greater interaction between these species and the AHS, with formation of chelates, a fraction forms hydroxides, while another fraction remains attached to the AHS, hence attracting the As(III) species. Melo et al. (2014) evaluated the release into water of $\mathrm{Fe}$ adsorbed on peat samples with high organic matter contents and observed that low Fe concentrations were released, proving the existence of strong interaction between $\mathrm{Fe}$ and the active sites of the OM. The results obtained in the present study are also in agreement with other published work (Liu and Cai 2010).

For the $\mathrm{As}(\mathrm{V})$ species, it was observed that the complexation by AHS decreased as the $\mathrm{pH}$ increased, with the highest $\mathrm{As}(\mathrm{V})$ concentrations bound by AHS (enriched with $\mathrm{Fe}$ or $\mathrm{Al}$ ) in an acidic medium ( $\mathrm{pH}$ 5.0). Metal ions ( $\mathrm{Fe}$ or $\mathrm{Al}$ ) assist the complexation reactions by forming bridges between $\mathrm{As}(\mathrm{V})$ 
and the AHS, so the better results obtained at slightly acidic $\mathrm{pH}$ can be explained by greater interaction of the metals with the AHS, because at low $\mathrm{pH}$ values, the $\mathrm{Al} / \mathrm{Fe}$ ions tend to be less hydroxylated and are preferably complexed by AHS. Therefore, higher concentrations of $\mathrm{As}(\mathrm{V})$, which in turn is in the form of negative ions at $\mathrm{pH}>2.0$, will bind to the metal-AHS complexes (AHS-Fe or AHS-Al) by means of electrostatic interactions, forming stable complexes.

After identifying the best complexation $\mathrm{pH}$, the As concentrations bound by the AHS samples were determined by plotting the free As fraction versus the total concentration of the As added (Fig. 4). The curves obtained showed a slope change, and the values of the As concentration complexed by AHS samples were obtained from the intersection of the two linear segments (Einax and Kunze 1996; Goveia et al. 2010). The amounts of As(III) bound by AHS-I-Fe and AHS-S-Fe were 67.7 and $73.8 \mu \mathrm{g} \mathrm{L}^{-1}$, respectively. Higher amounts of $\mathrm{As}(\mathrm{V})$ were bound by AHS samples when compared with the As (III) species. In terms of $\mathrm{As}(\mathrm{V})$ concentrations complexed, the order of complexing agents was: AHS-I-Al $<$ AHS-S-Al $<$ AHS-I-Fe $<$ AHS-S-Fe. Therefore, greater interactions were observed for the AHS samples enriched with $\mathrm{Fe}$, which was expected due to the higher affinity between the Fe and As species (Liu et al. 2011; Ritter et al. 2006).

The similar values found for the two AHS samples can be explained by the great similarity in their chemical compositions. The slightly higher value obtained for AHS-S enriched with metals, as well as the in natura sample (AHS-S), could have been due to small differences (higher levels) in the percentage amounts of ethers and aromatic hydroxyl groups, in addition to the aromaticity content (Table 2), because these groups are responsible for the binding of $\mathrm{As}(\mathrm{V})$ by AHS.

The complexation capacity (CC) values were determined according to Eq. 2:

$C C=\frac{[A s]_{b}}{[T O C]}$

where

$[\mathrm{As}]_{\mathrm{b}}=$ As concentration bound by AHS;

$[\mathrm{TOC}]=$ total organic carbon concentration of the AHS solution.

The $\mathrm{CC}$ values obtained are given in Table 3. The values found for complexation between $\mathrm{As}(\mathrm{V})$ and AHS-Fe or AHS-Al were similar to those described by Sharma, Ofner, and Kappler (2010), who reported values of 3.5-8.0 mg of As (V) $\mathrm{g}^{-1}$ of TOC. The values determined for the As(III) species were lower than that reported by Liu and Cai (2010). The difference can be explained by the different quantities of the metal ions complexed by the AHS.

\section{Binding mechanisms of arsenic by AHS}

In addition to the use of fluorescence spectroscopy to study the properties of HS, it is also widely applied to observe the mechanisms of interaction with inorganic compounds. Changes in fluorescence intensity, as well as wavelength shifts, can be indicative of binding of arsenic species by AHS and/or changes in the redox state of the HS. The samples were therefore subjected to fluorescence analysis in order to better understand the interactions of the AHS, $\mathrm{As}(\mathrm{V})$, and iron/aluminum (Fig. 5).

By comparing the spectra obtained for the solutions of AHS-S in natura and enriched with metals ( $\mathrm{Al}$ or $\mathrm{Fe}$ ), after reaction with the $\mathrm{As}(\mathrm{V})$ species, differences were observed in the fluorescence intensities of the regions related to humic and fulvic acids. The spectrum for the AHS-As(V) sample revealed small differences in emission intensities in the presence of $\mathrm{As}(\mathrm{V})$, using the same excitation wavelengths $(\lambda \mathrm{ex} / \lambda \mathrm{em}$ $\sim 250 />450$ and $\lambda \mathrm{ex} / \lambda \mathrm{em}>280 />380$ ), indicating changes in the structures of fulvic and humic acids. The AHS-S-Fe-As (V) spectrum showed large reductions in the intensities in the regions $\lambda \mathrm{ex} / \lambda \mathrm{em} \sim 250 />450$ and $\lambda \mathrm{ex} / \lambda \mathrm{em}>280 />380$. The spectrum of AHS-Al-As(V) showed regions with small displacements and reduced fluorescence intensities. The most intense peak at $\lambda \mathrm{ex} / \lambda \mathrm{em}$ of $250 / 450$ was the same before and after complexation reactions in the presence of iron or aluminum, indicating an absence of redox reactions in AHS-S.

The results showed the binding of As(V) by the AHS, with the greatest changes in the fluorescence spectra observed for the AHS enriched with metals, reflecting high concentrations of complexed $\mathrm{As}(\mathrm{V})$.

Recent studies have shown that metal cations can negatively influence the binding of arsenic (As(III) and As(V)) by HS, because when a metal is included in the complexation reaction, it tends to actively compete with arsenic for the humic and fulvic acid binding sites (Buschmann et al. 2006). However, when the metal cation is introduced earlier, allowing the reaction to reach equilibrium, a positive effect is observed. Metal cations play an important role, because they mediate the binding, acting as bridges between the $\mathrm{OM}$ and the $\mathrm{H}_{2} \mathrm{AsO}_{3}{ }^{-}, \mathrm{HAsO}_{3}{ }^{2-}, \mathrm{H}_{2} \mathrm{AsO}_{4}{ }^{-}$, and $\mathrm{HAsO}_{4}{ }^{2-}$ species, increasing the $\mathrm{As}(\mathrm{V})$ concentration bound by AHS due to the provision of a greater number of binding sites. Mikutta and Kretzchmar (2011) investigated the complexation of As(V) by HS in the presence of Fe(III), using EXAFS analysis, and observed that $\mathrm{As}(\mathrm{V})$ ions were bound to AHS by the formation of ternary complexes, with the Fe(III) mediating the binding of arsenate in the AHS active sites (phenolic, carboxylic, and hydroxyl groups). This was also found by Sharma, Ofner, and Kappler (2010) and de Oliveira, L.K. et al. (2015), using the infrared spectroscopy technique.

One pathway for the reaction of As with AHS-M involves the nucleophilic attack of the hydroxyl group attached to the 

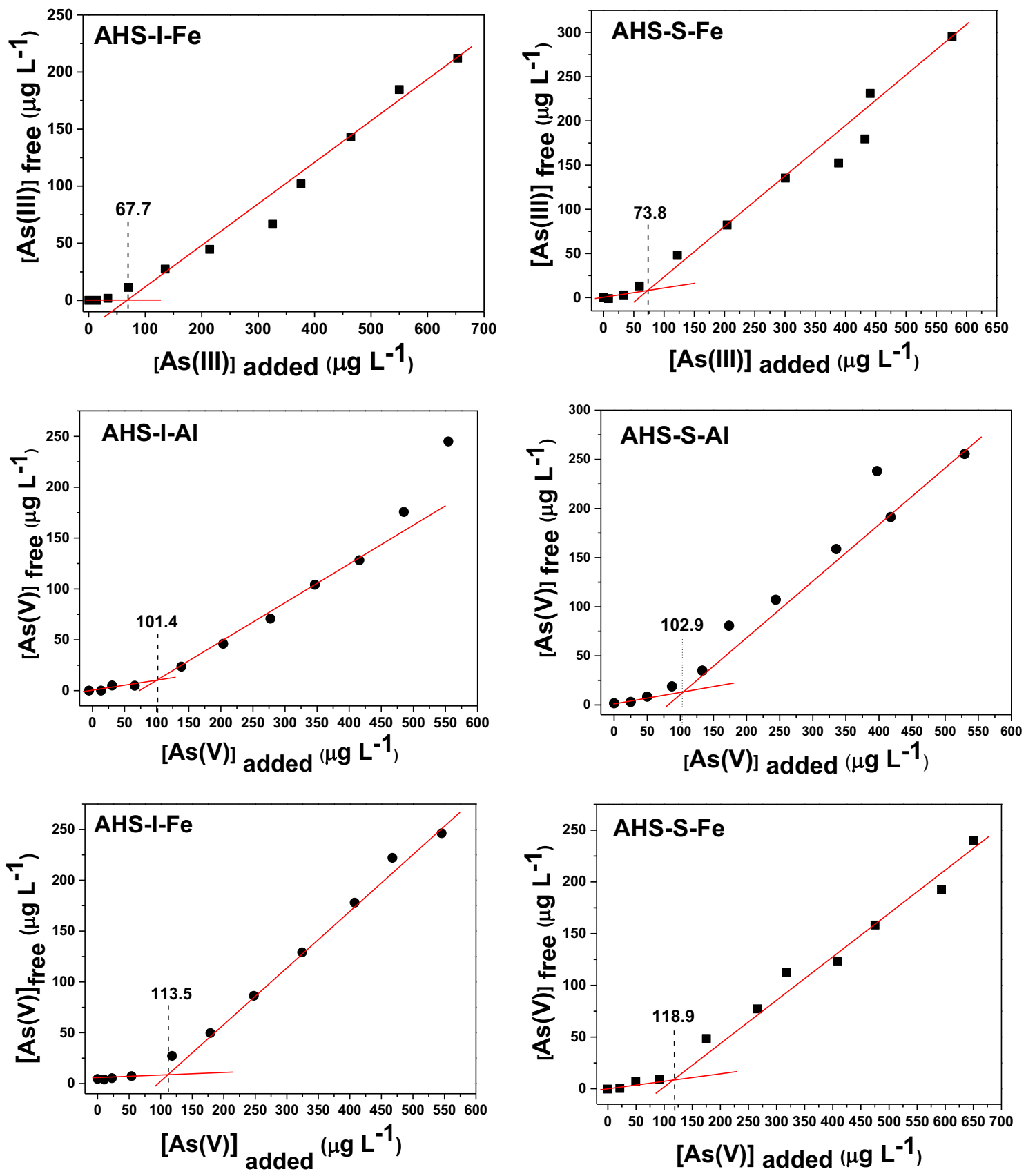

Fig. 4 As complexation capacity of AHS enriched with metals assessed by stepwise As species loading followed by ultrafiltration

Table 3 Complexation capacity (CC) values for interaction of As(III) and $\mathrm{As}(\mathrm{V})$ species with the AHS samples enriched with metals ( $\mathrm{Fe}$ or $\mathrm{Al})$

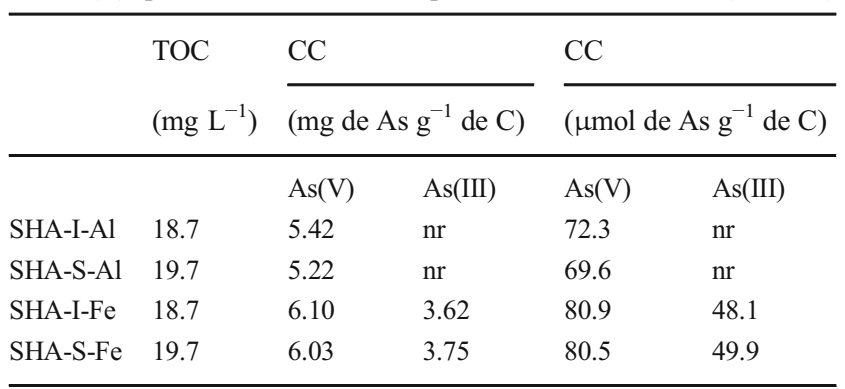

TOC total organic carbon, $n r$ no reaction, $C C$ complexation capacity metal $(\mathrm{Al}$ or $\mathrm{Fe})$ in the AHS-M chelate. However, this reaction only occurs after binding of the metal cation to the carboxylic and phenolic groups present in the AHS and stabilization of the complex formed (Fig. 6). This mechanism could describe the complexation for both $\mathrm{As}(\mathrm{V})$ and $\mathrm{As}(\mathrm{III})$ species by AHS-M. The reaction also occurs by electrostatic interactions, where the negative charges of arsenate ions are attracted to the positively charged groups of AHS-M, followed by the formation of strong bonds between the metal and $\mathrm{As}(\mathrm{V})$. Another route for As(III) involves the attack of their electron 

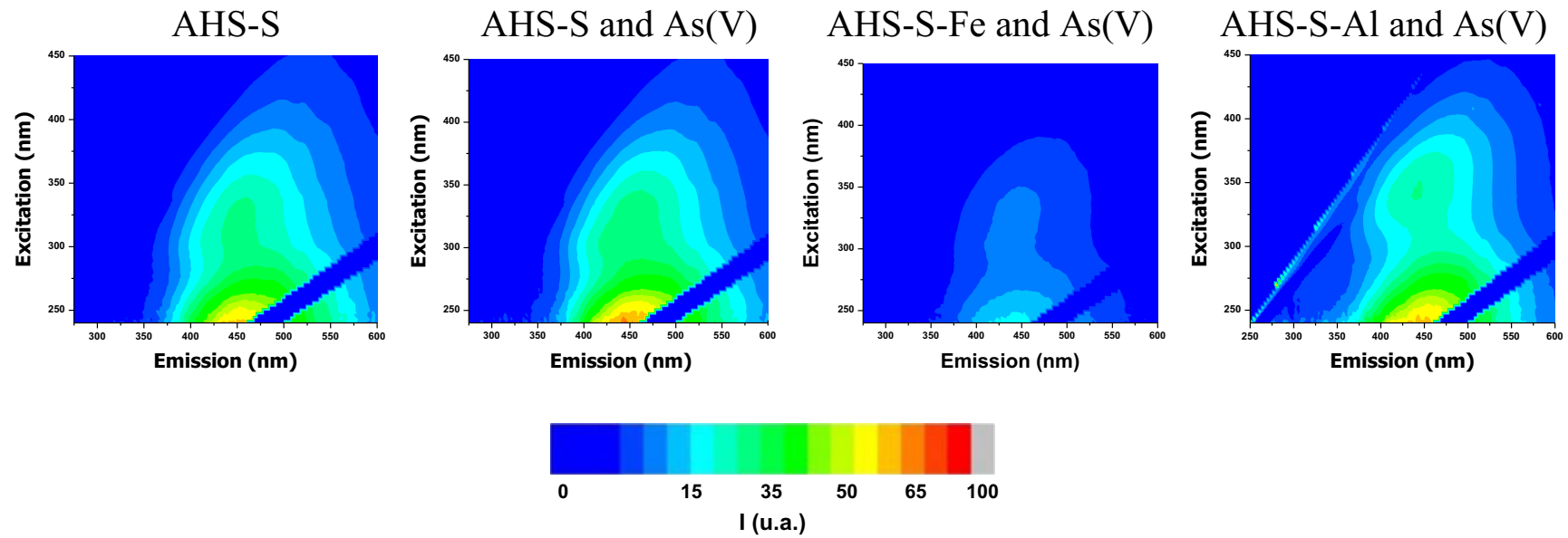

Fig. 5 Excitation-emission matrices (EEM) for the solutions of AHS-S, AHS-S-As(V), AHS-S-Fe-As(V), and AHS-S-Al-As(V) after $1 \mathrm{~h}$ of reaction at $\mathrm{pH} 7.0$

pair on the metallic cation creating a new covalent bound between the AHS-M chelate entre As(III) species (Buschmann et al. 2006).

\section{Influence of redox potential (Eh) on the As(V) complexation reactions}

In order to evaluate the influence of Eh on the complexation reactions of arsenic with AHS-Fe/AHS-Al, experiments using $\mathrm{As}(\mathrm{V})$ species and AHS-S samples in natura or enriched with aluminum or iron were conducted over $8 \mathrm{~h}$ under constant flows of $\mathrm{N}_{2}$ or $\mathrm{O}_{2}$. Fluorescence spectroscopy was used to analyze the complexation reactions between $\mathrm{As}(\mathrm{V})$ and the AHS samples. The effects of different Eh conditions are shown in Fig. 7. In tests conducted under $\mathrm{N}_{2}$ flow, where the change in Eh was 227 $<$ Eh $<64$ (lower Eh values), there were large changes in intensity and shifts of the regions in the fluorescence spectra corresponding to fulvic and humic acids, at $\lambda_{\mathrm{ex}} / \lambda_{\mathrm{em}} \sim 250 /$ $>450$ and $\lambda_{\mathrm{ex}} / \lambda_{\mathrm{em}}>280 />380$, respectively. These were due to the links formed between the metal cations and/or arsenic and the AHS. Changes in these regions were also observed in the tests conducted under $\mathrm{O}_{2}$ flow $(98<\mathrm{Eh}<481)$.

The effects caused by different redox conditions were investigated further by plotting the data in order of emission at a fixed wavelength between 250 and $350 \mathrm{~nm}$ (Fig. 8). Greater changes in the fluorescence intensities of the samples AHS-S, AHS-S-Al, and AHS-S-Fe (with $\lambda_{\text {exc }}$ fixed at 250 or $325 \mathrm{~nm}$ ) were observed under flows of $\mathrm{O}_{2}$, together with small shifts for the samples enriched with aluminum. There were also small reductions in intensities when the samples in the microcosms were purged constantly with $\mathrm{N}_{2}$. These changes indicated that differences in Eh affected the complexation of the $\mathrm{As}(\mathrm{V})$ species by the AHS, with the most pronounced effects for the AHS samples enriched with metals. Lower intensities under lower
Fig. 6 Proposed mechanism for the complexation between $\mathrm{As}(\mathrm{V})$ and AHS enriched with metals (Al or $\mathrm{Fe}$ )

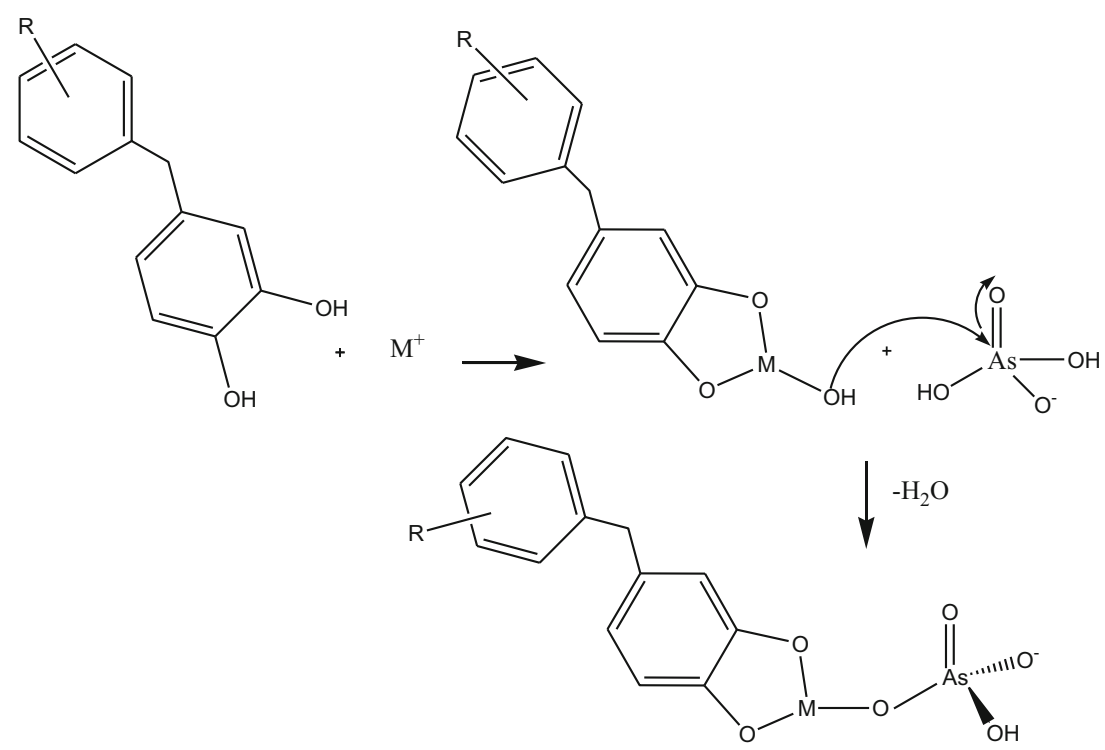



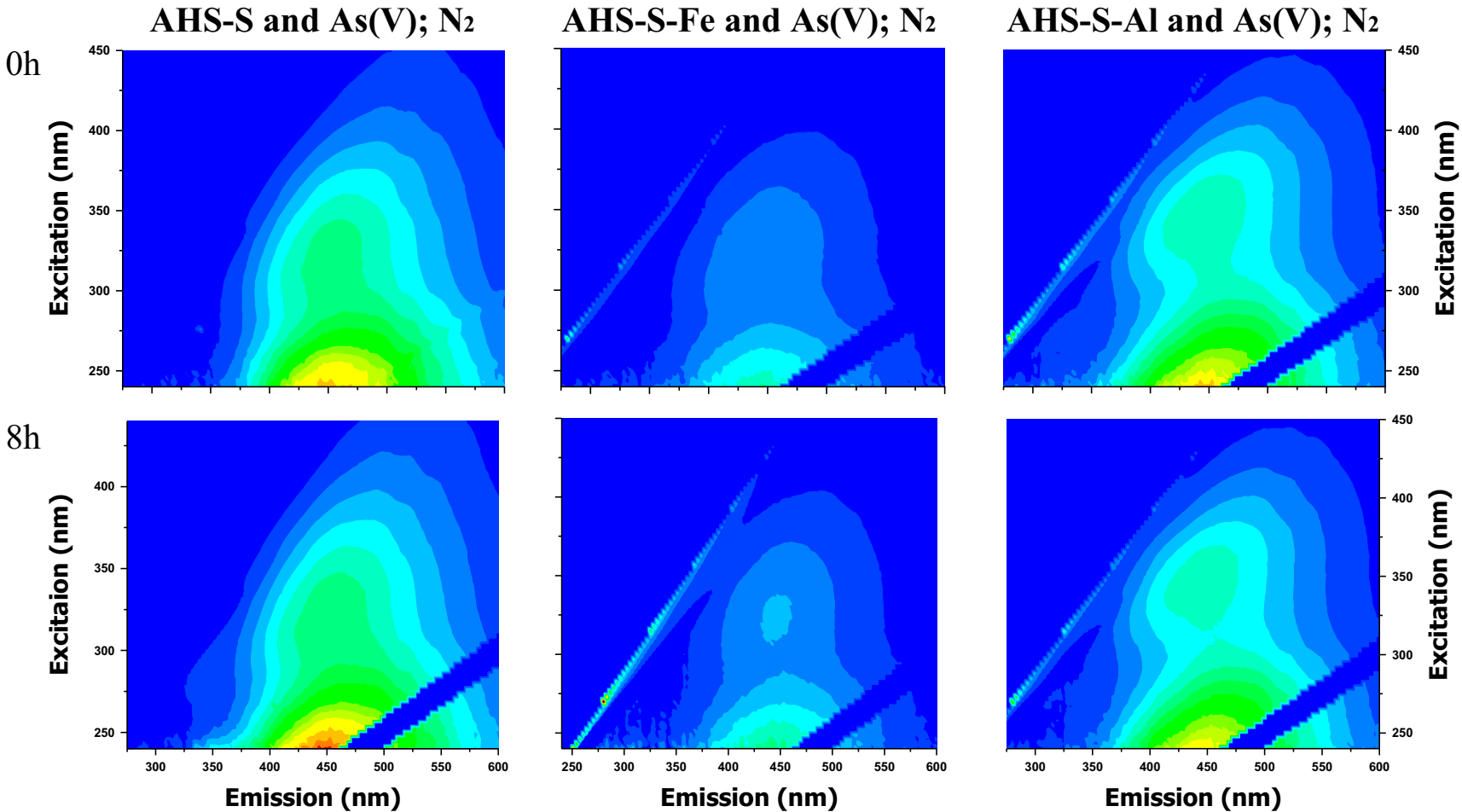

Fig. 7 EEMs for the samples AHS-S and As(V), AHS-S-Fe and As(V), and AHS-S-Al and As(V), under $\mathrm{N}_{2}$ flow

Eh values $(64<\mathrm{Eh}<227)$ could indicate the reduction of As(V) to As(III), which has higher mobility and lower affinity for the AHS (in natura or enriched with metals), as observed in previous data of this present work. However, to prove this information, more studies must be made to evaluate the As speciation change. The higher fluorescence intensities observed under oxidizing conditions indicated higher levels of $\mathrm{As}(\mathrm{V})$ species bound to the AHS. In addition, the concentrations of bound arsenic are dependent on the concentrations of iron associated with the AHS, because these ions are reduced and released to the solution as the Eh decreases (Molinari et al. 2013).

(a)

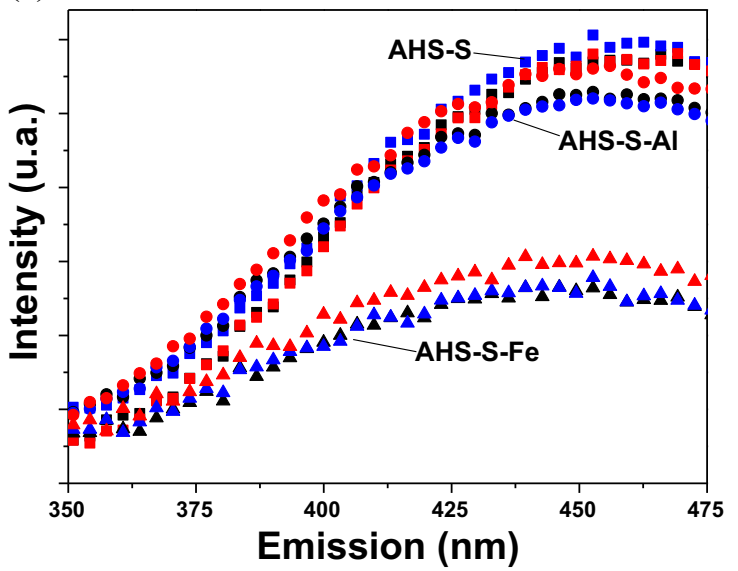

\section{Conclusions}

The findings of this work demonstrated that there was no interaction between As(III) and AHS in natura or enriched with $\mathrm{Al}(\mathrm{III})$. As(V) could bind, in low amounts (approximately $6 \%$ of the initial concentration), directly to the in natura AHS as well as by formation of ternary complexes with $\mathrm{Al} / \mathrm{Fe}$ and the AHS. The presence of metals significantly increased the quantities of arsenic complexed by the AHS, illustrating the importance of the cations in the formation of complexes with AHS. It was shown that the complexation of $\mathrm{As}(\mathrm{V})$

(b)

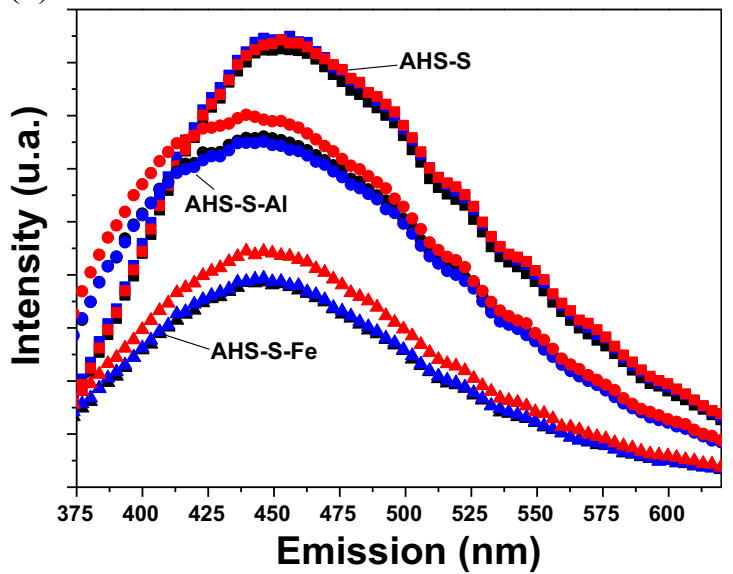

Fig. 8 Fluorescence emission spectra for AHS-S in natura (squares) or enriched with $\mathrm{Al}$ (III) (circles) or Fe(III) (triangle), under flows of $\mathrm{N}_{2}$ (blue) or $\mathrm{O}_{2}$ (red), using a $\lambda_{\text {exc }}$ fixed at $250 \mathrm{~nm}$ and $\mathbf{b} \lambda_{\text {exc }}$ fixed at $325 \mathrm{~nm}$ 
decreased with increasing $\mathrm{pH}$, while complexation of As(III) increased with increasing $\mathrm{pH}$. The complexation capacity for As(III) was $48 \mu \mathrm{mol}$ per gram of C, while for As(V), it was in the range of 69-80 $\mu \mathrm{mol}$ per gram of C. The influence of low concentrations of $\mathrm{Al}(\mathrm{III})$ and $\mathrm{Fe}$ (III) cations on the interaction of As with the AHS was confirmed using fluorescence spectra, which also showed that variation of Eh affected the complexation reactions of $\mathrm{As}(\mathrm{V})$ species with AHS.

This work contributes to a better understanding of the processes of interaction between arsenic species and the organic matter present in AHS, as well as the behavior of this element in the presence of iron and aluminum. Overall, the results demonstrated that the organic matter amount and the chemical composition of the medium influence the bioavailability of arsenic in aquatic environments. The presence of metals complexed by AHS (iron or aluminum) tends to reduce As mobility, because the metal cations act as bridges between the arsenic and the functional groups present in the AHS, with formation of ternary complexes. The results of this study have important environmental implications since it is shown that the availabilities of organic matter, iron, and aluminum play essential roles in the biogeochemical cycling of arsenic in the aquatic environment.

Acknowledgements The authors thank CAPES (BEX 18302-12-2), CNPQ, and FAPESP for financial support and scholarships. Also, to Burkhard Kuehn from UFZ by technical assistance with the microcosm unit and Dr. Peter Herzsprung from UFZ that introduced the first author into the EEMF method.

\section{References}

Batista APS, Romao LPC, Arguelho M, Garcia CAB, Alves JPH, Passos EA, Rosa AH (2009) Biosorption of Cr(III) using in natura and chemically treated tropical peats. J Hazard Mater 163:517-523

Borba RP, Figueiredo BR, Matschullat J (2003) Geochemical distribution of arsenic in waters, sediments and weathered gold mineralized rocks from Iron Quadrangle, Brazil. Environ Geol 44:39-52

Botero WG, de Oliveira LC, Cunha BB, de Oliveira LK, Goveia D, Rocha JC, Fraceto LF, Rosa AH (2011) Characterization of the Interactions between endocrine disruptors and aquatic humic substances from tropical rivers. J Braz Chem Soc 22:1103-1110

Burba P, Van den Bergh J, Klockow D (2001) On-site characterization of humic-rich hydrocolloids and their metal loading by means of mobile size-fractionation and exchange techniques. Fresenius J Anal Chem 371:660-669

Buschmann J, Kappeler A, Lindauer U, Kistler D, Berg M, Sigg L (2006) Arsenite and arsenate binding to dissolved humic acids: Influence of $\mathrm{pH}$, type of humic acid, and aluminum. Environ Sci Technol 40: 6015-6020

Chen W, Westerhoff P, Leenheer JA, Booksh K (2003) Fluorescence excitation - emission matrix regional integration to quantify spectra for dissolved organic matter. Environ Sci Technol 37:5701-5710

de Figueiredo BR, Borba RP, Angelica MS (2007) Arsenic occurrence in Brazil and human exposure. Environ Geochem Health 29:109-118

de Oliveira LK, Melo CA, Goveia D, Lobo FA, Hernandez MAA, Fraceto LF, Rosa AH (2015) Adsorption/desorption of arsenic by tropical peat: influence of organic matter, iron and aluminium. Environ Technol 36:149-159

Einax J, Kunze C (1996) Complexation capacity of aquatic systems in dependence on different ligands and heavy metals - electroanalytical investigations and statistical evaluation. Fresenius J Anal Chem 354:895-899

Frohne T, Rinklebe J, Diaz-Bone RA, Du Laing G (2011) Controlled variation of redox conditions in a floodplain soil: impact on metal mobilization and biomethylation of arsenic and antimony. Geoderma 160:414-424

Girouard E, Zagury GJ (2009) Arsenic bioaccessibility in CCAcontaminated soils: Influence of soil properties, arsenic fractionation, and particle-size fraction. Sci Total Environ 407:2576-2585

Goveia D, Lobo FA, Burba P, Fraceto LF, Dias Filho NL, Rosa AH (2010) Approach combining on-line metal exchange and tangential-flow ultrafiltration for in-situ characterization of metal species in humic hydrocolloids. Anal Bioanal Chem 397:851-860

Grafe M, Eick MJ, Grossl PR (2001) Adsorption of arsenate (V) and arsenite (III) on goethite in the presence and absence of dissolved organic carbon. Soil Sci Soc Am J 65:1680-1687

Gungor EBO, Bekbolet M (2010) Zinc release by humic and fulvic acid as influenced by $\mathrm{pH}$, complexation and DOC sorption. Geoderma 159:131-138

Li P, Wang YH, Jiang Z, Jiang HC, Li B, Dong HL, Wang YX (2013) Microbial diversity in high arsenic goundwater in Hetao Basin of Inner Mongolia, China. Geomicrobiol J 30:897-909

Limousin G, Gaudet JP, Charlet L, Szenknect S, Barthes V, Krimissa M (2007) Sorption isotherms: a review on physical bases, modeling and measurement. Appl Geochem 22:249-275

Liu GL, Cai Y (2010) Complexation of arsenite with dissolved organic matter conditional distribution coefficients and apparent stability constants. Chemosphere 81:890-896

Liu GL, Fernandez A, Cai Y (2011) Complexation of arsenite with humic acid in the presence of ferric iron. Environ Sci Technol 45:3210-3216

Mak MSH, Lo IMC (2011) Influences of redox transformation, metal complexation and aggregation of fulvic acid and humic acid on $\mathrm{Cr}(\mathrm{VI})$ and As(V) removal by zero-valent iron. Chemosphere 84:234-240

Mandal SK, Ray R, Chowdhury C, Majumder N, Jana TK (2013) Implication of organic matter on arsenic and antimony sequestration in sediment: evidence from Sundarban Mangrove Forest, India. Bull Environ Contam Toxicol 90:451-455

Melo CA, De Toffoli AL, Moreira AB, Bisinoti MC (2012) Solar radiation effect on the complexation capacity of aquatic humic substances with metals. J Braz Chem Soc 23:1871-1879

Melo CA, de Oliveira LK, Goveia D, Fraceto LF, Rosa AH (2014) Enrichment of tropical peat with micronutrients for agricultural applications: evaluation of adsorption and desorption processes. J Braz Chem Soc 25:36-49

Mikutta C, Kretzschmar R (2011) Spectroscopic evidence for ternary complex formation between arsenate and ferric iron bomplexes of humic dubstances. Environ Sci Technol 45:9550-9557

Molinari A, Guadagnini L, Marcaccio M, Straface S, Sanchez-Vila X, Guadagnini A (2013) Arsenic release from deep natural solid matrices under experimentally controlled redox conditions. Sci Total Environ 444:231-240

Mora A, Alfonso JA, Sanchez L, Calzadilla M, Silva S, LaBrecque JJ, Azocar JA (2009) Temporal variability of selected dissolved elements in the lower Orinoco River, Venezuela. Hydrol Process 23:476-485

Pimentel HS, de Lena JC, Nalini HA (2003) Studies of water quality in the Ouro Preto region, Minas Gerais, Brazil: the release of arsenic to the hydrological system. Environ Geol 43:725-730

Plaza C, D'Orazio V, Senesi N (2005) Copper(II) complexation of humic acids from the first generation of EUROSOILS by total luminescence spectroscopy. Geoderma 125:177-186 
Pokrovsky OS, Schott J (2002) Iron colloids/organic matter associated transport of major and trace elements in small boreal rivers and their estuaries (NW Russia). Chem Geol 190:141-179

Ritter K, Aiken GR, Ranville JF, Bauer M, Macalady DL (2006) Evidence for the aquatic binding of arsenate by natural organic matter-suspended Fe(III). Environ Sci Technol 40:5380-5387

Rosa AH, Rocha JC, Furlan M (2000) Humic substances of peat: study of the parameters that influence on the process of alkaline E extraction. Quim Nov. 23:472-476

Ruiz SH, Wickramasekara S, Abrell L, Gao XD, Chefetz B, Chorover J (2013) Complexation of trace organic contaminants with fractionated dissolved organic matter: implications for mass spectrometric quantification. Chemosphere 91:344-350

Santin C, Gonzalez-Perez M, Otero XL, Vidal-Torrado P, Macias F, Alvarez MA (2008) Characterization of humic substances in salt marsh soils under sea rush (Juncus maritimus). Estuar Coast Shelf Sci 79:541-548

Sargentini E, Rocha JC, Rosa AH, Zara LF, Santos A (2001) Aquatic humic substances: molecular size fractionation and characterization of inner rearrangements after metal ions complexation. Quim Nov. 24:339-344

Sarkar S, Greenleaf JE, Gupta A, Ghosh D, Blaney LM, Bandyopadhyay P, Biswas RK, Dutta AK, SenGupta AK (2010) Evolution of community-based arsenic removal systems in remote villages in West Bengal, India: assessment of decade-long operation. Water Res 44:5813-5822
Sharma P, Ofner J, Kappler A (2010) Formation of binary and ternary colloids and dissolved complexes of organic matter, Fe and As. Environ Sci Technol 44:4479-4485

Sharma P, Kappler A (2011) Desorption of arsenic from clay and humic acid-coated clay by dissolved phosphate and silicate. J Contam Hydrol 126:216-225

Sharma VK, Sohn M (2009) Aquatic arsenic: toxicity, speciation, transformations, and remediation. Environ Int 35:743-759

Song S, Lopez-Valdivieso A, Hernandez-Campos DJ, Peng C, MonroyFernandez MG, Razo-Soto I (2006) Arsenic removal from higharsenic water by enhanced coagulation with ferric ions and coarse calcite. Water Res 40:364-372

Thurman EM, Malcolm RL (1981) Preparative isolation of aquatic humic substances. Environ Sci Technol 15:463-466

Wang SL, Mulligan CN (2006) Effect of natural organic matter on arsenic release from soils and sediments into groundwater. Environ Geochem Health 28:197-214

Warwick P, Inam E, Evans N (2005) Arsenic's interaction with humic acid. Environ Chem 2:119-124

Winter AR, Fish TAE, Playle RC, Smith DS, Curtis PJ (2007) Photodegradation of natural organic matter from diverse freshwater sources. Aquat Toxicol 84:215-222

Yu KW, Bohme F, Rinklebe J, Neue HU, DeLaune RD (2007) Major biogeochemical processes in soils - a microcosm incubation from reducing to oxidizing conditions. Soil Sci Soc Am J 71:1406-1417

Zhou P, Yan H, Gu BH (2005) Competitive complexation of metal ions with humic substances. Chemosphere 58:1327-1337 